\title{
STRATEGI PENGEMBANGAN OBYEK WISATA ALAM \\ BUMI PERKEMAHAN LELES TAMAN NASIONAL GUNUNG CIREMAI
}

\author{
Amellya Clanandika ${ }^{1)}$, Yayan Hendrayana ${ }^{2)}$, Nurdin ${ }^{3)}$ \\ ${ }^{1}$ Program Studi Kehutanan, Fakultas Kehutanan Universitas Kuningan \\ 2013071004@uniku.ac.id \\ ${ }^{2}$ Program Studi Kehutanan, Fakultas Kehutanan Universitas Kuningan \\ yayan.hendrayana@uniku.ac.id \\ ${ }^{3}$ Program Studi Kehutanan, Fakultas Kehutanan Universitas Kuningan \\ nurdin@uniku.ac.id
}

\begin{abstract}
Abstrak
Wisata Alam Bumi Perkemahan Leles TNGC dikelola secara swadaya dalam kelompok Mitra Pariwisata Gunung Ciremai (MPGC). Pada tahun 2017 mengalami penurunan jumlah pengunjung sehingga perlu mengetahui potensi yang dimiliki dan menyusun strategi pengembangan untuk meningkatkan minat pengunjung. Peneilitian dilaksanakan di kawasan Obyek Wisata Alam Bumi Perkemahan Leles Taman Nasional Gunung Ciremai. Metode yang digunakan untuk mengetahui potensi adalah metode eksploratif sedangkan untuk menyusun strategi pengembangan menggunakan analisis SWOT, dimana analisis SWOT mengidentifikasi faktor internal dan eksternal, memetakan posisi pengembangan dan membuat strategi pengembangan dengan matriks SWOT. Potensi yang dimiliki Bumi Perkemahan Leles yaitu keindahan alam, Curug Leles, Taman Air Terjun, Camping Ground, Tenjo Gunung serta Flora dan Fauna. Strategi pengembangan yang diterapkan yaitu dengan cara mengembangkan semua potensi-potensi yang dimiliki bekerjasama dengan masyarakat sekitar dengan merancang design yang unik serta menumbuhkan dan meningkatkan sadar konservasi melalui pendidikan dan penyuluhan kepada masyarakat, pengelola dan pengunjung serta tetap mempertahankan daya tarik kawasan wisata yang khas dengan melestarikannya, contohnya pohon Leles (Ficus glandulifera). Kawasan wisata alam Bumi Perkemahan Leles bisa dijadikan sebagai wisata pendidikan untuk pelajar yang berkunjung dengan menambah pengetahuan pelajar mengenai jenis satwa dan tumbuhan. Memelihara fasilitas yang ada agar bisa digunakan untuk jangka panjang serta untuk kenyamanan pengunjung.
\end{abstract}

Kata Kunci : Analisis SWOT; Strategi pengembangan; Bumi Perkemahan Leles TNGC.

\section{PENDAHULUAN}

Wisata Alam Bumi Perkemahan Leles memiliki banyak daya tarik untuk dikembangkan, diantaranya: pemandangan yang indah, udara yang sejuk, air terjun, camping ground, taman air terjun, serta potensi flora salah satunya jenis Leles (Ficus glanduifera) yang dijadikan sebagai potensi unggulan dengan keunikannya, serta terdapat jenis-jenis burung di kawasan Bumi perkemahan Leles Taman Nasional Gunung Ciremai (TNGC).

Menurut hasil wawancara dengan MPGC bahwa selama 3 tahun terakhir jumlah wisatawan mengalami peningkatan, yaitu tahun 2014 (875 pengunjung), 2015 (1.600 pengunjung), 2016 (2.150 pengunjung), akan tetapi pada tahun 2017 jumlah wisatawan yang berkunjung mengalami penurunan (1.705 pengunjung).

\section{METODE PENELITIAN}

\section{A. Tempat dan Waktu Penelitian}

Penelitian dilaksanakan pada bulan OktoberNovember 2017, berlokasi di Obyek Wisata Alam Bumi Perkemahan Leles Taman Nasional Gunung. Luas kawasan Obyek Wisata Alam Bumi Perkemahan Leles adalah 3 Ha dengan ketinggian mencapai $400 \mathrm{mdpl}$. 


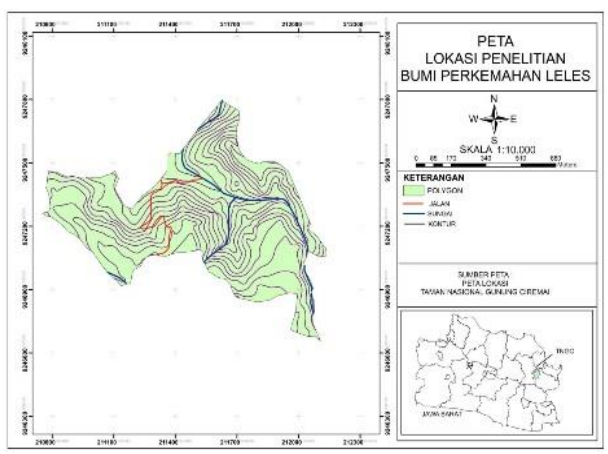

Gambar 1. Lokasi Penelitian

\section{B. Alat dan Bahan}

Alat yang digunakan dalam penelitian ini diantaranya adalah: Alat tulis, Global Positioning System (GPS), Kuisioner, Kamera, Alat perekam suara (recorder). Sedangkan bahan penelitian yang digunakan adalah Obyek Wisata Alam Bumi Perkemahan Leles, Responden, vegetasi dan satwa.

\section{Jenis dan Sumber Data}

Data primer adalah data yang diperoleh secara langsung dari lapangan dari objek penelitian atau dari lapangan melalui observasi seperti potensi kawasan, promosi, sarana dan prasarana/fasilitas, potensi bencana alam, aksesibilitas, estetika.

Data sekunder diperoleh dari studi literatur, dan informasi yang ada dilokasi penelitian dan instansi terkait seperti kondisi umum kawasan yang meliputi: kondisi fisik kawasan, kondisi biologi kawasan. Kondisi demografi, sosial dan ekonomi masyarakat sekitar.

\section{Metode Pengumpulan Data}

1) Observasi

Pencatatan data dilakukan berdasarkan penemuan langsung di lapangan meliputi : potensi kawasan, keadaan fisik kawasan, dan aksesibilitas. Adapun pengambilan data potensi dengan menggunakan metode eksploratif yaitu survei untuk melakukan penjelajahan (Fathoni, 2011). Penyebaran potensi kawasan yang terdapat di lapangan ditandai dengan posisi menggunakan GPS.

2) Wawancara

Wawancara dilaksanakan pada pengelola dan masyarakat sekitar Obyek Wisata Alam Bumi Perkemahan Leles

3) Kuisioner

Kuisioner dilaksanakan pada pengunjung Obyek Wisata Alam Bumi Perkemahan Leles Taman Nasional Gunung Ciremai.

\section{E. Metode Pengambilan Sampel}

Pengambilan sampel untuk pengelola dan masyarakat sekitar Obyek Wisata Alam Bumi Perkemahan Leles dengan menggunakan metode Porposive Sampling yaitu memilih sampel secara sengaja kepada ketua MPGC, kepala desa, perangkat desa serta masyarakat sekitar. sedangkan pengambilan sampel untuk pengunjung menggunakan metode simple random sampling yakni dengan memilih sampel secara acak dengan jumlah 100 responden.

\section{F. Metode Analisis Data}

Analisis data dilakukan dengan menggunakan metode Analisis SWOT yang dapat menggambarkan secara jelas bagaimana peluang dan ancaman eksternal yang dihadapi dapat disesuaikan dengan faktor internal (kekuatan dan kelemahan) yang dimiliki (Rangkuti, 2002 dalam Yanto, 2010).

\section{* Penentuan Pembobotan}

Menentukan nilai analisis SWOT dilakukan dengan pembobotan dari hasil penyebaran kuisioner yang diberikan kepada pengunjung, pengelola, dan masyarakat sekitar. Pembobotan tersebut yaitu :

1) Skala pengukuran

Hasil kuisioner yang diberikan kepada pengunjung yang bersifat kualitatif di kuantitatifkan dengan skala mulai dari 4 (sangat penting), sampai 1 (tidak penting). Setelah seluruh hasil kuisioner dihitung kemudian

dilanjutkan dengan mengidentifikasi faktorfaktor strategis internal dan eksternal Kawasan Wisata Alam Curug Leles, dengan menggunakan metode pembobotan (skoring).

\section{- Matrik Faktor Internal dan Eksternal}

Setelah penghitungan pembobotan selesai dilakukan selanjutnya membuat faktor strategi eksternal dan internal, dengan langkah sebagai berikut:

1) Menentukan faktor-faktor yang menjadi kekuatan serta kelemahan yang terdapat di Obyek Wisata Alam Bumi Perkemahan Leles dalam kolom 1.

2) Memberi bobot masing-masing faktor tersebut dengan skala dari 1,0 (paling penting) sampai 0,0 (tidak penting), berdasarkan pengaruh faktor-faktor tersebut terhadap posisi strategis di Obyek Wisata Alam Bumi Perkemahan Leles. Semua bobot tersebut jumlahnya tidak lebih dari satu berdasarkan pengaruh dan kondisi Wisata Alam Bumi Perkemahan Leles. 
3) Menentukan rating, variabel yang bersifat positif (semua yang masuk kategori kekuatan dan peluang) diberi nilai mulai dari +1 sampai dengan +3 (sangat baik), untuk variabel yang bersifat negatif adalah sebaliknya.

4) Kalikan bobot pada kolom 2 dengan rating pada kolom 3.

5) Jumlahkan skor pembobotan untuk memperoleh total skor, untuk menentukan posisi pengembangan dalam kuadran SWOT.

Tabel 1. Faktor Internal dan Eksternal

\begin{tabular}{lccc}
\hline \multicolumn{1}{c}{ Kolom 1 } & Kolom 2 & Kolom 3 & Kolom 4 \\
\hline $\begin{array}{c}\text { Faktor } \\
\text { internal }\end{array}$ & Bobot & Rating & $\begin{array}{c}\text { Skor } \\
\text { Pembobotan }\end{array}$ \\
\hline Kekuatan & & & \\
Jumlah S & & & \\
Kelemahan & & & \\
Jumlah W & & & \\
Jumlah S+W & & & \\
\hline
\end{tabular}

Tabel 2. Faktor Internal dan Eksternal

\begin{tabular}{lccc}
\hline Kolom 1 & Kolom 2 & Kolom 3 & Kolom 4 \\
\hline $\begin{array}{c}\text { Faktor } \\
\text { eksternal }\end{array}$ & Bobot & Rating & $\begin{array}{c}\text { Skor } \\
\text { Pembobotan }\end{array}$ \\
\hline Peluang & & & \\
Jumlah O & & & \\
Ancaman T & & & \\
Jumlah T & & & \\
Jumlah O+T & & & \\
\hline
\end{tabular}

Keterangan :

Kolom 1: Faktor-faktor yang dimiliki oleh kawasan wisata diantaranya Kekuatan, Kelemahan, Peluang, dan Ancaman.

Kolom 2: Bobot daripada faktor internal dan eksternal kawasan wisata.

Kolom 3: Rating dari faktor Internal dan eksternal kawasan wisata.

Kolom 4: Skor pembobotan dimana skor pembobotan adalah hasil daripada bobot $\mathrm{x}$ rating.

Membuat kuadran SWOT untuk memetakan posisi pengembangan Kawasan Wisata Alam Curug Leles sebagai berikut :

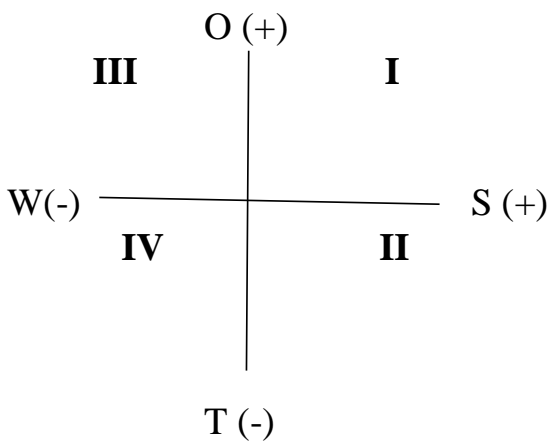

Gambar 2. Posisi strategi

Obyek Wisata Alam Bumi Perkemahan Leles TNGC

Keterangan :

Kuadran I: Merupakan situasi yang sangat menguntungkan, artinya suatu kawasan wisata tersebut memiliki peluang dan kekuatan sehingga dapat memanfaatkan peluang yang ada.

Kuadran II: Meskipun menghadapi ancaman, kawasan wisata masih memiliki kekuatan dari segi internal. Strategi yang harus ditetapkan adalah menggunakan kekuatan untuk memanfaatkan peluang.

Kuadran III: Kawasan wisata menghadapi peluang besar akan tetapi menghadapi beberapa kelemahan internal. Strategi kawasan wisata ini adalah meminimalisir masalah internal kawasan wisata sehingga dapat merebut peluang yang lebih baik.

Kuadran IV: Merupakan situasi yang tidak menguntungkan dimana kawasan wisata menghadapi berbagai ancaman dan kelemahan internal.

\section{Matrik SWOT}

Untuk menyusun strategi pengembangan berdasarkan analisis SWOT, maka diperlukan Matrik. Matrik ini dapat menghasilkan empat kemungkinan alternatif strategis. Dengan enggunakan faktor strategis internal dan eksternal, serta peluang dan ancaman dari tabel faktor internal dan ekternal ke dalam tabel matriks SWOT sebagai berikut : 


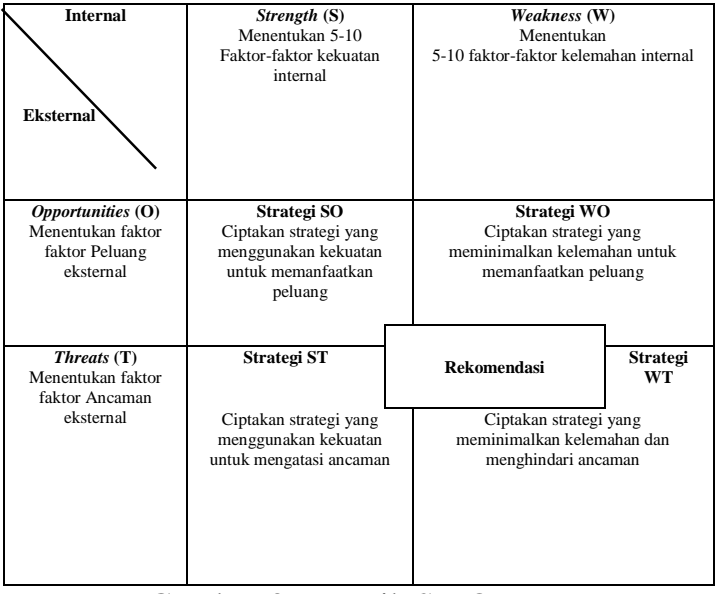

Gambar 3. Matrik SWOT

(Rangkuti 2006 dalam Lucyanti et al 2014)

\section{HASIL DAN PEMBAHASAN}

\section{A. Potensi Obyek Wisata Alam Bumi Perkemahan Leles Taman Nasional Gunung Ciremai}

Obyek Wisata Alam Bumi Perkemahan Leles TNGC memiliki daya tarik panorama alam yang indah dan menarik serta memiliki potensi yang baik untuk dikembangkan sebagai tempat rekreasi dan wisata alam yang dapat menarik minat pengunjung, potensi yang terdapat didalamnya adalah potensi panorama alam serta potensi flora dan fauna.

\section{B. Potensi Panorama Alam}

\section{Curug Leles}

Memiliki ketinggian $\pm 7 \mathrm{~m}$, suhu rata - rata $27^{\circ} \mathrm{C}$ dan air yang jernih dengan debit air yang cukup deras meskipun pada musim kemarau.

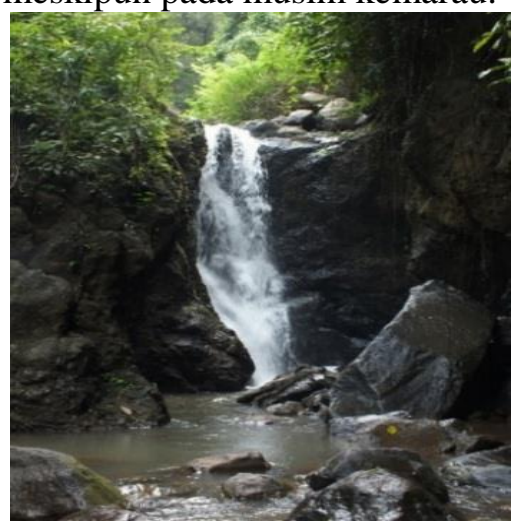

Gambar 4. Curug Lele

\section{Camping Ground}

Ukuran lahan untuk tenda berkemah ini yaitu 2,6 $\mathrm{m} \times 2,8 \mathrm{~m}$, luas area berkemah ini yaitu $350 \times 70$ $m$ dibagi menjadi tiga area yaitu blok $\mathrm{A}, \mathrm{B}$, dan C. daya tampung blok A 50 tenda, blok B 25 tenda.

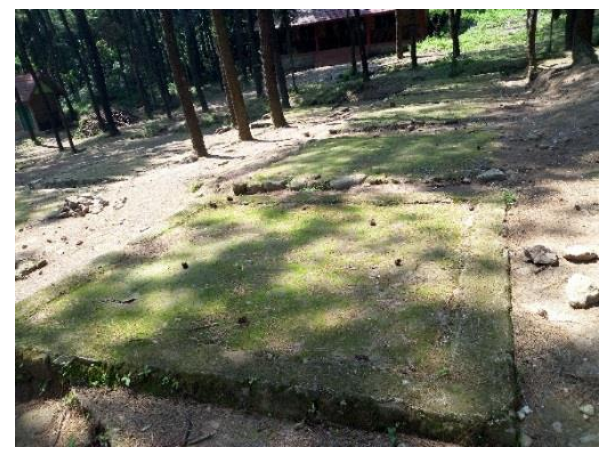

Gambar 5. Camping Ground

\section{Tenjo Gunung}

Tenjo Gunung merupakan spot area untuk menikmati pemandangan alam dari atas Buper Leles, pemandangan tersebut diantaranya Gunung Kuda/Gunung Kapur, wilayah pusat kota majalengka dan keindahan hamparan sawah masyarakat sekitar Kawasan.

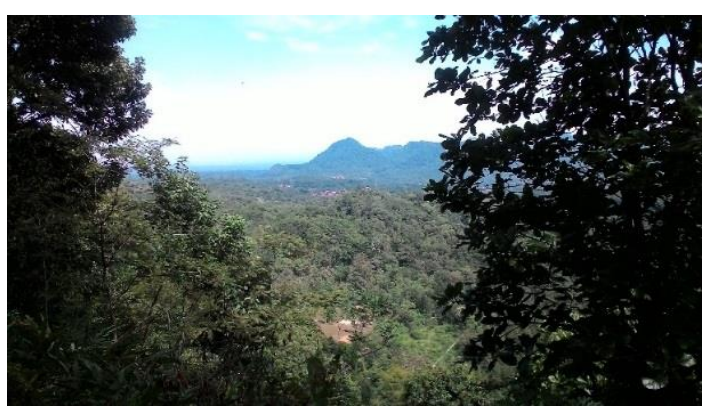

Gambar 6. Tenjo Gunung

\section{Taman Air Terjun}

Memiliki luasan $15 \times 10 \mathrm{~m}$, suhu rata-rata di area ini yaitu $29^{\circ} \mathrm{C}$ lokasi ini banyak digunakan untuk spot selfie oleh pengunjung.

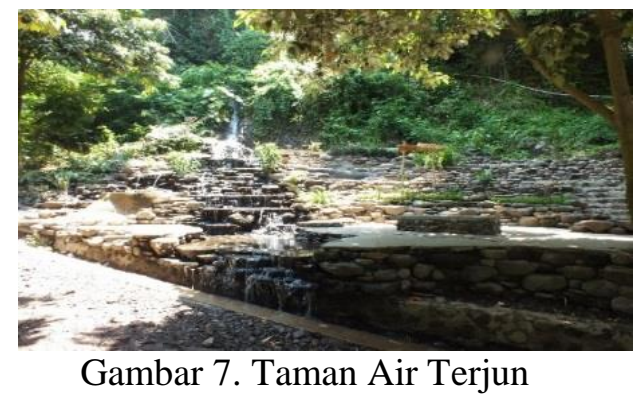

\section{Potensi Flora dan Fauna}

1. Flora

Berdasarkan hasil eksplorasi jenis flora yang ditemukan di sekitar Bumi Perkemahan Leles yaitu sebanyan 42 jenis. 
Tabel 3. Jenis Flora yang ditemukan di Buper Leles TNGC

\begin{tabular}{|c|c|c|}
\hline No & Nama Lokal & Nama Spesies \\
\hline 1 & Aren & Arenga pinnata \\
\hline 2 & Benda & Artocarpus elastica \\
\hline 3 & Beringin & Ficus benjamina \\
\hline 4 & Binuang & Octomeles sumatrana Miq \\
\hline 5 & Caruy & Pterospermum acerifolium \\
\hline 6 & Durian & Durio zibethinus \\
\hline 7 & Gintung & Bischofia javanica \\
\hline 8 & Hantap & Sterculia urceolata \\
\hline 9 & Huru Dapung & Actinoddaphne glomerata \\
\hline 10 & Huru Hiris & Litsea $S p$ \\
\hline 11 & Iplik & Ficus $S p$ \\
\hline 12 & Jati Putih & Gmelina arborea \\
\hline 13 & Junti & \\
\hline 14 & Kalapa Ciung & Horsfieldia glabra \\
\hline 15 & Kamuning & Murraya paniculata \\
\hline 16 & Karanginan & \\
\hline 17 & Kaliandra & Calliandra haematocephala \\
\hline 18 & Kelapa & Cocos nucifera \\
\hline 19 & Kibrahma & \\
\hline 20 & Kicangkudu & Fagraea racemosa \\
\hline 21 & Kihiyang & Albizia precera \\
\hline 22 & Kihonje & Pittosporum ferruineum Aiton \\
\hline 23 & Kimeong & Mallotus philippinensis \\
\hline 24 & Kipepetek & \\
\hline 25 & kisampang & Evodia lativolia \\
\hline 26 & Kiteja & Cinamomum sintok \\
\hline 27 & Коро & Eugenia subglauca \\
\hline 28 & Leles & Ficus glandulifera \\
\hline 29 & Mahoni & Swietenia macrophylla \\
\hline 30 & Manglid & Manglietia glauca Blum \\
\hline 31 & Mara & Macaranga rhicinoides \\
\hline 32 & Melinjo & Gnetum gnemon \\
\hline 33 & Nangsi & Villebrunea rubescens \\
\hline 34 & Pangsor & Ficus callosa \\
\hline 35 & Рepaya & Carica papaya \\
\hline 36 & Peutag & Eugenia uniflora $L$ \\
\hline 37 & Picung & Pangium edule \\
\hline 38 & Pinang & Areca catechu \\
\hline 39 & Pinus & Pinus mercusii \\
\hline 40 & Pisang & Musa paradisiaca spp \\
\hline 41 & Putat & Planchonia valida \\
\hline 42 & Wuni & Antidesma bunius \\
\hline
\end{tabular}

Data ini menunjukkan bahwa kondisi lingkungan sekitar objek harus benar-benar dijaga dan dipelihara agar vegetasi yang telah ada tetap terpelihara, kekayaan potensi keragaman hayati flora yang dimiliki dapat menunjang atau menambah daya tarik wisatawan untuk melihat berbagai jenis tumbuhan disekitar Obyek Wisata Alam (Latupapua, 2007).
Menurut MPGC salah satu jenis tumbuhan yang dijadikan sebagai potensi obyek daya tarik untuk pengunjung yaitu jenis tumbuhan Leles (Ficus glandulifera) dikarenakan bentuk yang unik dan menurut pengelola hanya ada satu individu di kawasan Buper Leles. Budidaya bisa dari biji (National Parks Board, 2013).

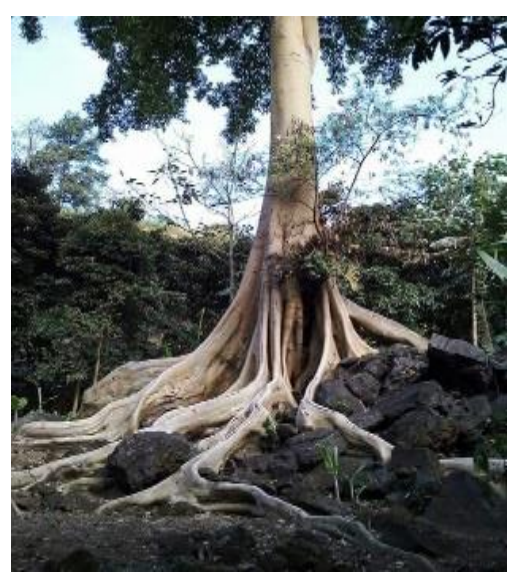

Gambar 8. Pohon Leles (Ficus glandulifera)

\section{Fauna}

Berdasarkan hasil pengamatan di Bumi Perkemahan Leles TNGC hanya ditemukan 4 jenis aves. Selengkapnya dapat dilihat pada tabel 3.2 .

Tabel 4. Jenis Satwa yang ditemukan di Buper Leles TNGC

\begin{tabular}{lll}
\hline No & \multicolumn{1}{c}{ Nama Lokal } & \multicolumn{1}{c}{ Nama Ilmiah } \\
\hline 1 & Elang Ular Bido & $\begin{array}{l}\text { Spilornis cheela } \\
\text { Pynonotus } \\
\text { caferaurigaster }\end{array}$ \\
2 & Kutilang & Streptopelia chinensis \\
3 & Tekukur biasa & Psilopogon lineatus \\
4 & Takur bultok & \\
\hline
\end{tabular}

Adapun berdasarkan hasil wawancara dengan warga sekitar, dapat ditemukan 18 jenis satwa yang berbeda. Diantaranya terdapat 5 jenis mamalia dan 13 jenis aves Selengkapnya dapat dilihat pada tabel 3.3 dan 3.4.

Tabel 5. Jenis Mamalia Hasil Wawancara

\begin{tabular}{cll}
\hline No & Nama Lokal & Nama Ilmiah \\
\hline 1 & Babi Hutan & Sus scrofa \\
2 & Kijang & Muntiacus muntjak \\
3 & Lutung Jawa & Trachypithecus auratus \\
4 & Monyet Ekor Panjang & Macaca fascicularis \\
5 & Musang & Paradoxurux \\
& & hermaproditu \\
\hline
\end{tabular}


Tabel 6. Jenis Aves Hasil Wawancara

\begin{tabular}{|c|c|c|}
\hline No & Nama Lokal & Nama Ilmiah \\
\hline 1 & Alap - alap & Falko moluccensis \\
\hline 2 & Betet Kelabu & Lanius schach \\
\hline 3 & Bondol jawa & $\begin{array}{l}\text { Lonchura } \\
\text { leucogastroides }\end{array}$ \\
\hline 4 & Caladi & Dendrocopos sp \\
\hline 5 & $\begin{array}{l}\text { Cekakak } \\
\text { Jawa }\end{array}$ & Halcyon cyanoventris \\
\hline 6 & $\begin{array}{l}\text { Cekakak } \\
\text { sungai }\end{array}$ & Halcyon chloris \\
\hline 7 & Cucak ijo & Chloropsis sonnerati \\
\hline 8 & Elang Hitam & Ictinaetus malayensis \\
\hline 9 & Jogjog & Pycnonotus goiavier \\
\hline 10 & $\begin{array}{l}\text { Kedasi/wiwik } \\
\text { kelabu }\end{array}$ & Cacomantis merulinus \\
\hline 11 & Srigunting & Dicrurus sp \\
\hline 12 & Walet & Apus affinis \\
\hline 13 & Walik & Ptilinopus sp \\
\hline
\end{tabular}

Potensi yang terdapat di buper Leles ditandai dengan pengambilan titik menggunakan GPS (Geographic Position System), Peta potensi Bumi Perkemahan Leles TNGC dapat dilihat pada gambar 3.6.

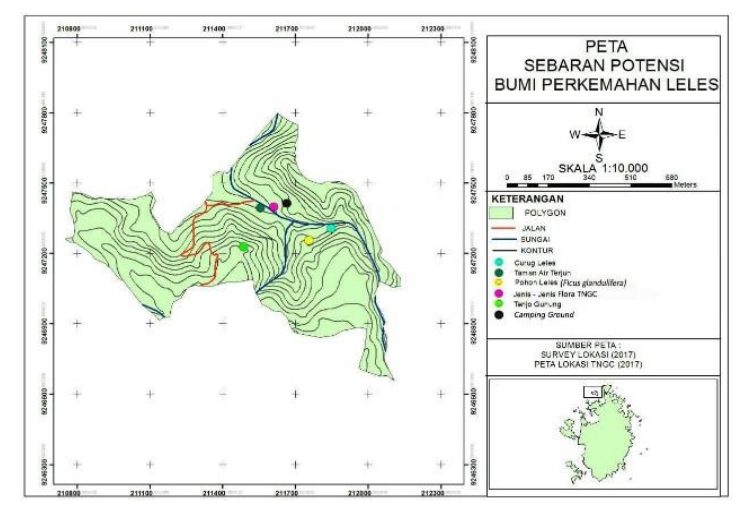

Gambar 9. Peta Sebaran Potensi

\section{Strategi Pengembangan Obyek Wisata Alam Bumi Perkemahan Leles Taman Nasional Gunung Ciremai}

Strategi pengembangan Obyek wisata Alam pada Kawasan Bumi Perkemahan Leles TNGC dirumuskan melalui analisis SWOT yang meliputi faktor internal yaitu terdapat 7 kekuatan dan 7 kelemahan serta faktor eksternal terdapat 3 peluang dan 3 ancaman yang dihasilkan dari pengamatan langsung dilapangan, kuisioner kepada pengunjung, serta wawancara kepada pengelola dan masyarakat sekitar.

\section{E. Faktor Internal (Kekuatan dan Kelemahan)}

\section{1) Kekuatan}

a. Estetika/keindahan alam

Kegiatan rekreasi obyek wisata alam Bumi Perkemahan Leles TNGC memiliki daya tarik yang indah, dengan pemandangan alam yang masih asri serta adanya pohon pinus (Pinus merkusii) yang membuat udara di Kawasan Buper Leles menjadi sejuk, serta terdapat pula atraksi/potensi wisata yang dapat menarik minat pengunjung.

\section{b. Keberadaan potensi}

Menurut (Aryanti, 2013) potensi masing-masing wisata harus ditonjolkan agar mampu menarik minat wisatawan untuk berkunjung ke wisata tersebut. Potensi yang terdapat didalam kawasan Bumi Perkemahan Leles, diantaranya adalah : Curug Leles, Tenjo Gunung View jenis flora dan fauna didalamnya, terdapat juga area untuk berfoto yang di design secara unik yaitu Taman Air Terjun, selain itu pengunjung yang ingin memulihkan rasa lelah disediakan tempat untuk beristirahat dan bermalam yaitu bumi perkemahan.

\section{c. Keberadaan tempat parkir}

Lahan parkir ini terletak di antara pohon pinus sehingga menciptakan suasana sejuk dan tidak panas. Menurut MPGC, lahan parkir ini mampu untuk menampung 200 kendaraan roda dua dan 15 kendaraan roda empat.

\section{d. Ketersediaan air bersih}

Ketersediaan air merupakan hal penting dalam suatu kehidupan tidak hanya untuk sektor rumah tangga, melainkan untuk sektor pariwisata dan industri. dengan adanya sumber air disekitarnya membuat obyek wisata buper Leles memiliki ketersediaan air bersih yang memadai.

\section{e. Ketersediaan MCK}

Berdasarkan pengamatan MCK yang tersedia di Buper Leles sudah memadai dan mampu untuk mengakomodir kebutuhan pengunjung ataupun bagi orang yang melakukan kegiatan camping. MCK ini sudah tersebar di setiap blok area camping. MCK yang tersebar di setiap blok dibangun dengan konsep satu bak untuk dua pintu MCK yang saling membelakangi.

f. Ketersediaan musholla

Terdapat satu buah musholla yang berada di Buper Leles ini. Musholla ini di design secara sederhana tapi cukup menarik dengan temboknya 
yang dikombinasi dengan anyaman bambu, musolla yang tersedia mampu untuk menampung \pm 15 -20 orang.

\section{g. Aksesibilitas}

Aksesibilitas adalah kemampuan suatu daerah untuk berhubungan dengan daerah lainnya. Tingginya aksesibilitas suatu daerah dapat menjadi potensi untuk pengembangan wilayah. Tingkat aksesibilitas suatu wilayah dicirikan dengan semakin baiknya kondisi jalan yang menghubungkan suatu daerah dengan daerah lain (Flamin dan Asnaryati, 2013).

\section{2) Kelemahan}

a. Kurangnya promosi

Menurut R.G. Soekadijo (2000) dalam Sovia Nuraeni (2014) promosi meliputi sejumlah kegiatan yang bertujuan untuk mempengaruhi, mengimbau dan merayu wisatawan potensial agar tertarik untuk melakukan perjalanan wisata.

Menurut hasil wawancara, Balai Taman Nasional Gunung Ciremai SPTN II Majalengka melakukan promosi berupa kegiatan pameran. kegiatan ini dilaksanakan satu tahun sekali. Bentuk promosi dalam pameran ini yaitu berupa pembagian brosur, dan gantungan berupa foto Obyek Daya Tarik Wisata serta menyajikan spanduk/banner berupa dokumentasi yang berkaitan dengan Obyek Wisata yang berada di SPTN II Majalengka, sedangkan Mitra Pengelola Gunung Ciremai Bumi Perkemahan Leles hanya mempromosikan melalui salah satu akun media sosial, sehingga penyampaian informasi kepada wisatawan belum optimal dilakukan.

\section{b. Kurangnya dukungan dana}

Menurut hasil wawancara dengan Ketua MPGC Bumi Perkemahan Leles, salah satu kelemahan Kawasan wisata adalah sulitnya mendapatkan dana, dimana kawasan wisata merupakan kawasan konservasi yang berada dalam wilayah Balai Taman Nasional Gunung Ciremai.

c. Kurangnya kualitas dan kuantitas SDM

Menurut (Parwoto, 2001) dalam (Zulhijja dan Azzuhri, 2014) Peningkatan kualitas SDM menjadi salah satu kunci untuk memenangkan persaingan global yang semakin kompetitif. Agar sdm memiliki kinerja yang baik maka harus meningkatkan sistem pendidikan dan pelatihan kepariwisataan yang mendukung penyusunan dan penerapan standar kompetensi tenaga kerja pariwisata.

Jumlah karyawan Obyek Wisata Alam Bumi Perkemahan Leles berjumlah 10 orang.
Berdasarkan wawancara dengan Ketua MPGC Bumi Perkemahan Leles dapat diketahui bahwa 5 orang atau $50 \%$ pernah mengikuti pendidikan dan pelatihan kepariwisataan dan 5 orang atau $50 \%$ belum pernah mengikuti pendidikan dan pelatihan kepariwisataan.

d. Kurangnya pengetahuan tentang jenis potensi flora dan fauna

Menurut Meyers (2009) kegiatan pariwisata yang dilakukan sebaiknya memberikan unsur pendidikan. Ini bisa dilakukan dengan beberapa cara antara lain dengan memberikan informasi menarik seperti nama dan manfaat tumbuhan dan hewan yang ada di sekitar daerah wisata, dapat didukung dengan penyebaran brosur atau pemasangan papan informasi.

e. Masih ada potensi yang belum dikembangkan Menurut wawancara dengan kelompok MPGC terdapat potensi di Buper Leles yang belum dikembangkan, potensi tersebut yaitu Tenjo Gunung. Berdasarkan hasil survey di kawasan selain bisa untuk melihat pemandangan alamnya Tenjo Gunung ini bisa dilakukan pula kegiatan penelitian burung untuk lebih menarik minat pengunjung khususnya para peneliti.

f. Kurangnya ketersediaan warung

Fasilitas yang tidak memadai di Buper Leles salah satunya adalah warung. Selain untuk membeli makanan warung bisa dijadikan untuk tempat beristirahat. Warung yang tersedia di Buper Leles berjumlah 3 warung, namun warung yang setiap hari berjualan hanya ada satu warung. Ketersediaan warung dalam suatu obyek wisata akan sangat membantu pengunjung untuk lebih menikmati wisata dengan nyaman (Ading, 2010).

g. Kurangnya ketersediaan tempat sampah

Berdasarkan pengamatan di lapangan Tempat sampah yang berada di kawasan ini berupa trash bag yang digantung atau diletakkan dekat dengan pohon, ketersediaan tempat sampah di Kawasan Buper masih kurang memadai sehingga membuat pengunjung kesulitan untuk membuang sampah.

\section{F. Faktor Eksternal (Peluang dan Ancaman)}

\section{1) Peluang}

a. Adanya kunjungan dari luar daerah

Wisatawan yang berkunjung ke Buper Leles berasal dari berbagai daerah, yaitu dari dalam Kota Majalengka dan luar Kota Majalengka

b. Banyaknya pelajar yang berkunjung Banyaknya pelajar/mahasiswa dalam rekreasi alam karena mereka termasuk wisatawan muda, 
perjalanan mereka tidak hanya sekedar rekreasi untuk menghilangkan kejenuhan, tetapi mereka juga berharap agar memperoleh berbagai pengalaman baru, bahkan ada pula pelajar dan mahasiswa yang berkunjung untuk menyelesaikan tugas dari Sekolah dan Universitas mereka masing-masing.

c. Dukungan Masyarakat sekitar

Salah satu faktor penentu keberhasilan pengembangan wisata di suatu daerah adalah sikap masyarakat lokal terhadap kegiatan tersebut, sikap masyarakat yang positif antara lain dapat terlihat dari peran serta dan keterlibatan mereka (Hakim, 2012).

Masyarakat berpendapat dengan keberadaan Buper Leles TNGC dapat menciptakan lapangan pekerjaan dan menambah pendapatan, berdasarkan hasil penelitian terdapat jenis usaha yang telah dilakukan masyarakat diantara.nya konsumsi (warung makanan dan minuman, catering) dan jasa (penitipan kendaraan).

\section{2) Ancaman}

a. Adanya persaingan dengan obyek wisata lain Berdasarkan pengamatan Kawasan wisata alam yang terdapat disekitar kawasan Bumi Perkemahan Leles diantaranya adalah wisata alam Talaga Herang, Bumi Perkemahan Talaga pancar, Situ Cikuda, Curug Baligo dan Curug Cipeteuy. Dengan banyaknya wisata alam disekitar Buper Leles menyebabkan persaingan antar obyek wisata, sehingga mengurangi jumlah wisatawan yang berkunjung. b. Adanya bencana alam

Berdasarkan pengamatan dan wawancara Obyek Wisata Alam Bumi Perkemahan Leles berpotensi terjadinya bencana alam, hujan yang cukup tinggi mengakibatkan kawasan ini rawan terhadap banjir dan longsor.

c. Adanya pencemaran lingkungan

Berdasarkan hasil pengamatan, kawasan Bumi Perkemahan Leles berpotensi adanya Pencemaran lingkungan. Dengan banyaknya sampah di sekitar kawasan dapat menyebabkan potensi alamiah rusak. Upaya pemahaman perilaku pengunjung terhadap lingkungan merupakan kajian yang menarik dan penting untuk dipelajari sebagai salah satu bentuk penyelamatan lingkungan. Salah satunya adalah meneliti faktor-faktor yang mempengaruhi perilaku wisatawan dalam menjaga kebersihan lingkungan (Darmawan dan Fadjarani, 2016).

\section{G. Analisis Matrik Faktor Strategi Internal dan Eksternal}

Setelah faktor-faktor strategis internal dan eksternal teridentifikasi maka dibuatlah tabel IFAS (Internal Factors Analysis Summary) untuk merumuskan faktor-faktor strategi internal dalam kerangka Strengths dan Weaknesses serta tabel EFAS (Eksternal Factors Analysis Summary) untuk merumuskann faktor-faktor strategi eksternal dalam kerangka Opportunities dan Threats. Tabel IFAS dan EFAS dapat dilihat pada Tabel 3.5 dan 3.6.

Tabel 7. IFAS (Internal Factors Analysis Summary)

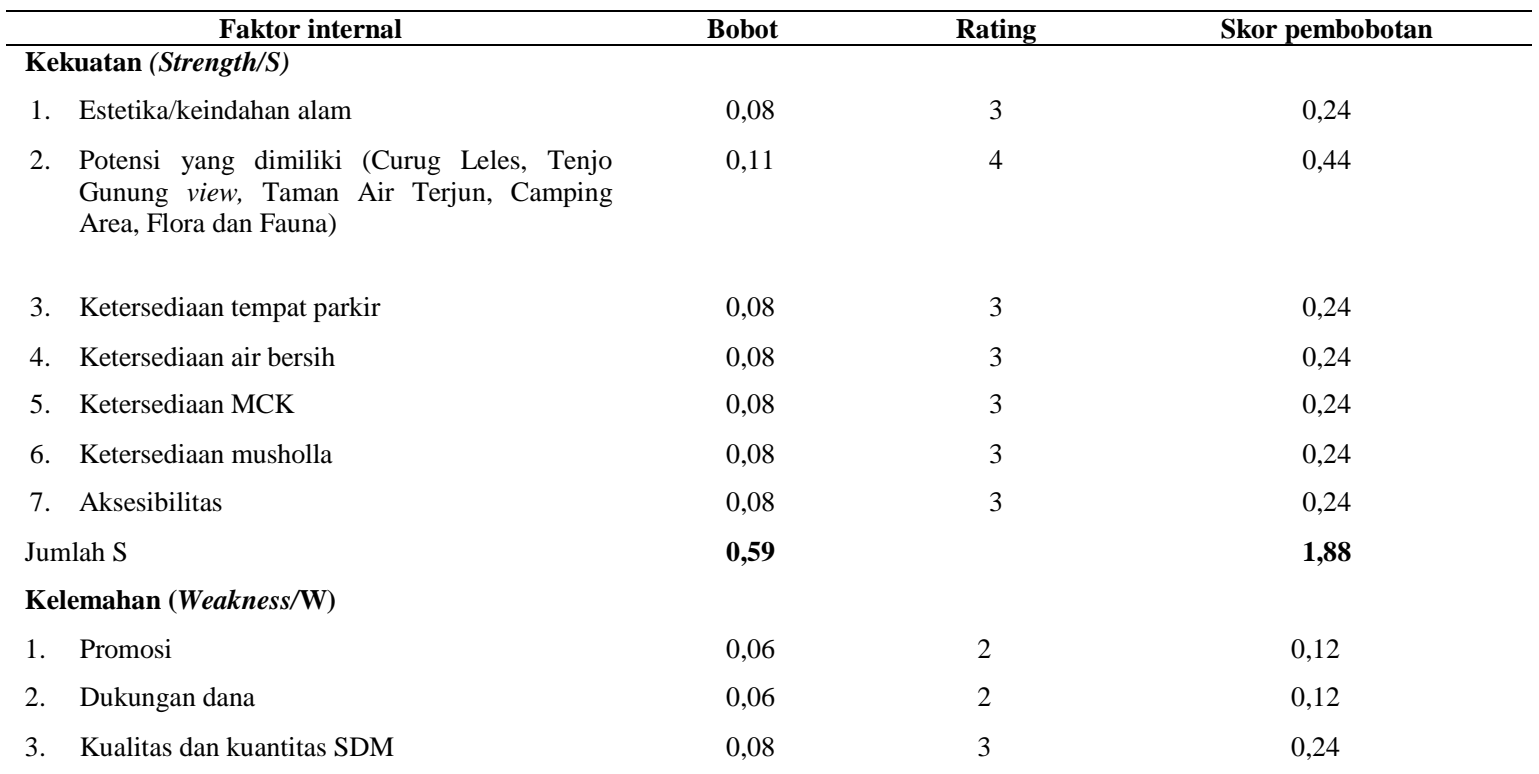


4. Pengetahuan tentang jenis potensi flora dan

0,06

0,06

0,06

6. Ketersediaan warung

7. Ketersediaan tempat sampah

Jumlah W

$\begin{array}{lll}0,06 & 2 & 0,12 \\ 0,06 & 2 & 0,12 \\ 06 & 2 & 0,12 \\ 0,03 & 1 & 0,03 \\ \mathbf{0 , 4 1} & & \mathbf{0 , 8 7}\end{array}$

$\mathrm{S}+\mathrm{W}=\mathbf{1 , 8 8}+\mathbf{0 , 8 7}=\mathbf{2 , 7 5}$

Tabel 8. EFAS (Eksternal Factors Analysis Summary)

\begin{tabular}{|c|c|c|c|}
\hline Faktor eksternal & Bobot & Rating & Skor pembobotan \\
\hline \multicolumn{4}{|l|}{ Peluang (Opportunities/O) } \\
\hline 1. Adanya kunjungan dari luar daerah & 0,18 & 3 & 0,54 \\
\hline 2. Banyaknya pelajar yang berkunjung & 0,18 & 3 & 0,54 \\
\hline 3. Dukungan Masyarakat sekitar & 0,18 & 3 & 0,54 \\
\hline Jumlah O & 0,54 & & 1,62 \\
\hline \multicolumn{4}{|l|}{ Ancaman (Threats/T) } \\
\hline 1. Persaingan dengan obyek wisata lain & 0,13 & 2 & 0,26 \\
\hline 2. Adanya bencana alam & 0,19 & 3 & 0,57 \\
\hline 3. Adanya pencemaran lingkungan & 0,13 & 2 & 0,26 \\
\hline Jumlah T & 0,45 & & 1.09 \\
\hline
\end{tabular}

Berdasarkan tabel diatas dapat diketahui bahwa skor untuk faktor internal adalah 2,75 dan skor untuk faktor eksternal adalah 2,71 dengan demikian posisi pengembangan berada pada kuadran I. Posisi tersebut dapat di lihat pada gambar 3.7.

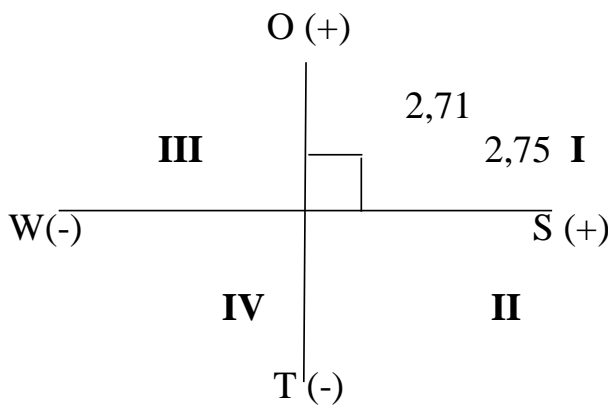

Gambar 10. Posisi pengembangan Buper Leles TNGC

Dari gambar diatas dapat disimpulkan bahwa posisi pengembangan Kawasan Wisata Alam Bumi Perkemahan Leles berada pada kuadran I yakni merupakan situasi yang sangat menguntungkan, artinya kawasan Obyek Wisata Alam Bumi Perkemahan Leles TNGC memiliki peluang dan kekuatan sehingga dapat memanfaatkan peluang yang ada.

\section{H. Perumusan Strategi Pengembangan Bumi Perkemahan Leles TNGC}

Untuk menyusun strategi pengembangan berdasarkan analisis SWOT, maka diperlukan Matrik. Matrik ini akan menggambarkan secara jelas tentang bagaimanaa peluang dan ancaman eksternal yang dihadapi dapat disesuaikan dengan kekuatan dan kelemahan internal yang dimiliki. Matrik ini dapat menghasilkan empat 
kemungkinan alternatif strategi, seperti tersaji pada gambar 3.8.

\begin{tabular}{|c|c|c|c|c|}
\hline EFAS & \multicolumn{2}{|c|}{\begin{tabular}{ll}
\multicolumn{2}{l}{ Kekuatan (Strength) } \\
1. & Estetika/keindahan kawasan di Buper Leles \\
& TNGC \\
2. & Potensi yang dimiliki Buper Leles TNGC \\
3. & Aksesibilitas menuju lokasi \\
4. & Ketersediaan air bersih \\
5. & Ketersediaan tempat parkir \\
6. & Ketersediaan MCK \\
7. & Ketersediaan musholla
\end{tabular}} & \multicolumn{2}{|c|}{$\begin{array}{l}\text { Kelemahan (Weakness) } \\
\text { 1. Promosi potensi } \\
\text { 2. Dukungan dana } \\
\text { 3. Kualitas dan kuantitas SDM } \\
\text { 4. Pengetahuan tentang jenis potensi flora dan } \\
\text { fauna } \\
\text { 5. Masih ada potensi yang belum dikembangkan } \\
\text { 6. Ketersediaan warung } \\
\text { 7. Ketersediaan tempat sampah }\end{array}$} \\
\hline $\begin{array}{ll}\text { Peluang (Opportunities) } \\
\text { 1. } & \begin{array}{l}\text { Adanya kunjungan dari luar } \\
\text { daerah }\end{array} \\
\text { 2. } & \begin{array}{l}\text { Banyaknya pelajar yang } \\
\text { berkunjung }\end{array} \\
\text { 3. } & \begin{array}{l}\text { Dukungan } \\
\text { sekitar }\end{array}\end{array}$ & $\begin{array}{l}\text { Strategi Strength-Opportunities (SO) } \\
\text { 1. Mengembangkan semua potensi y } \\
\text { dan mempertahankan daya } \\
\text { bekerjasama antar pihak pengelola } \\
\text { dan pengunjung. } \\
\text { 2. Dengan banyaknya } \\
\text { pelajar yang berkunjung, } \\
\text { kawasan wisata } \\
\text { bisa memanfaatkan SDA sebagai } \\
\text { pendidikan } \\
\text { 3. Mempertahankan } \\
\text { fasilitas/sarana dan prasarana } \\
\text { yang ada }\end{array}$ & $\begin{array}{rr} & \\
\text { ng dimiliki } \\
\text { ik } \quad \text { wisata } \\
\text { masyarakat } \\
\\
\\
\text { ana } & \\
& \text { Rek }\end{array}$ & $\begin{array}{l}\text { Strategi Weakn } \\
\text { 1. Meningkatkan } \\
\text { 2. Koordinasi da } \\
\text { daerah dengar } \\
\text { 3. Meningkatka } \\
\text { 4. Membuat pa } \\
\text { flora dan faur } \\
\text { 5. Meningkatka }\end{array}$ & $\begin{array}{l}\text { s-Opportunities (WO) } \\
\text { promosi potensi } \\
\text { bekerjasama antar pemerintah } \\
\text { instansi terkait } \\
\text { kualitas dan kuantitas SDM } \\
\text { an informasi mengenai jenis } \\
\text { yang berada di Kawasan } \\
\text { jumlah fasilitas }\end{array}$ \\
\hline $\begin{array}{l}\text { Ancaman (Threats) } \\
\text { 1. Persaingan dengan obyek } \\
\text { wisata lain } \\
\text { 2. Adanya bencana alam } \\
\text { 3. Adanya pencemaran } \\
\text { lingkungan }\end{array}$ & $\begin{array}{l}\text { Strategi Strength- } \\
\text { Threath } \text { (ST) } \\
\text { 1. obyek wisata Buper leles } \\
\text { harus memiliki nilai } \\
\text { tambah berupa keindahan dan } \\
\text { keunikan daya tarik wisata } \\
\text { 2. Perlu adanya pemeliharaan } \\
\text { fasilitas } \\
\text { 3. Perlu adanya pelebaran } \\
\text { dan perbaikan jalan } \\
\text { 4. Perlindungan dan } \\
\text { pengamanan kawasan dari } \\
\text { bencana alam dan pencemaran } \\
\text { lingkungan., serta } \\
\text { membuat papan peringatan. } \\
\text { 5. Mengikutsertakan masyarakat do } \\
\text { wisata. }\end{array}$ & 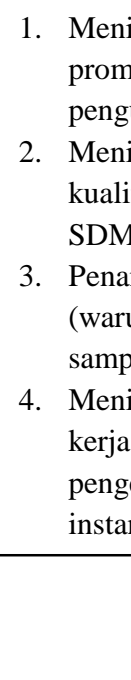 & $\begin{array}{l}\text { gkatkan } \\
\text { si kepada } \\
\text { njung } \\
\text { gkatkan } \\
\text { s dan kuantitas } \\
\text { bahan fasilitas } \\
\text { gg dan tempat } \\
\text { h) } \\
\text { gkatkan } \\
\text { ama antara } \\
\text { lola dan } \\
\text { si lain }\end{array}$ & \begin{tabular}{|l} 
kness- \\
Threath (WT) \\
1. Dengan adanya persaingan \\
dengan objek wisata \\
lainnya, pengelola dan \\
BTNGC harus \\
meningkatkan promosi \\
potensi secara kolaboratif, \\
dan meningkatkan jumlah \\
fasilitas \\
2. Meningkatkan \\
Profesionalisme SDM, \\
pengelola ran dan \\
meningkatkan peran serta \\
masyarakat \\
3. Adanya bencana alam dan \\
pencemaran lingkungan \\
membuat pengelola, desa, \\
dan BTNGC harus \\
memperhatikan kondisi \\
objek tersebut.
\end{tabular} \\
\hline
\end{tabular}

Gambar 11. Matrik SWOT Strategi Pengembangan Obyek Wisata Alam Bumi Perkemahan Leles

Berdasarkan matrik SWOT diatas maka dapat disusun langkah strategi pengembangan SO (Strengths-Opportunities) yaitu mendukung strategi agresif di Bumi Perkemahan Leles TNGC yakni merupakan situasi yang sangat menguntungkan, artinya suatu kawasan wisata tersebut memiliki peluang dan kekuatan sehingga dapat memanfaatkan peluang yang ada.Strategi yang harus diterapkan di Obyek wisata ini yaitu dengan mengembangkan semua potensi panorama alam yang dimiliki, serta menjaga potensi flora dan fauna bekerjasama dengan masyarakat sekitar serta pengunjung, yakni dengan cara memberi nilai tambah berupa keindahan dan keunikan daya tarik wisata yang telah ada, pada curug leles bisa dilakukannya penataan sekitar area curug Leles dengan design yang menarik dan nyaman yaitu bisa diberikan lahan untuk berenang dan diberikan nuansa batu - batu yang tersusun secara unik dan tertata rapih. Di kawasan Tenjo Gunung, pengelola bisa merancang design dengan membuat rumah pohon, jembatan pandang, serta membuat keunikan untuk spot selfie lainnya misalnya rumah kurcaci, rumah gorila, serta bisa dibuat juga taman bunga untuk lebih memberikan 
nuansa yang indah, hal tersebut bisa diterapkan pula pada area Camping Ground.

Untuk menjaga kelestarian flora dan fauna harus ada kerjasama antar semua pihak, BTNGC harus menumbuhkan dan meningkatkan sadar konservasi melalui pendidikan dan penyuluhan kepada pengelola dan masyarakat sekitar kemudian pengelola harus melaksanakan sosialisasi tentang pentingnya konservasi kepada pengunjung bisa dengan secara langsung maupun dengan cara pembagian brosur atau dengan penambahan papan informasi untuk tidak merusak keindahan lingkungan dengan cara membuang sampah pada tempatnya agar tidak terjadi pencemaran lingkungan, serta untuk tetap menjaga keberadaan tumbuhan dan satwa yang berada di Obyek Wisata Alam Bumi Perkemahan Leles TNGC. Pengelola juga harus mengenalkan atau mempromosikan jenis tumbuhan dan satwa yang terdapat di Buper Leles untuk lebih menarik minat pengunjung. Salah satu tumbuhan yang dijadikan sebagai obyek daya tarik wisata yaitu Leles (Ficus glandulifera), namun menurut pengeloa tumbuhan Leles (Ficus glandulifera) yang terdapat di kawasan Buper Leles hanya ada satu individu, maka untuk mempertahankan keberadaannya pengelola bisa melakukan budidaya melalui biji dari pohon Leles (Ficus glandulifera) bekerjasama dengan pihak BTNGC dan masyarakat sekitar.

Dengan banyaknya pelajar yang berkunjung, kawasan wisata bisa dijadikan sebagai wisata pendidikan untuk pelajar yang berkunjung dengan menambah pengetahuan pelajar mengenai jenis satwa dan tumbuhan serta manfaatnya, dengan memberikan papan penamaan pada tumbuhan, dan papan informasi tentang jenis satwa dan titik keberadaannya. Wisata edukasi atau edutourism adalah suatu konsep perpaduan antara kegiatan wisata dengan kegiatan pembelajaran, wisatawan berkunjung ke suatu lokasi wisata dengan tujuan utama untuk memperoleh pengalaman pembelajaran secara langsung di obyek wisata tersebut. (Rodger, 1998 dalam Priyanto et al., 2018). Mempertahankan fasilitas/sarana dan prasarana dengan cara pemeliharaan yang baik agar bisa digunakan dalam jangka panjang dan untuk kenyamanan pengunjung serta harus menambah fasilitas yang kurang memadai diantaranya tempat sampah dan warung, perlu adanya pelebaran dan perbaikan jalan serta penambahan papan petunjuk jalan untuk lebih memudahkan perjalanan wisatawan.

\section{SIMPULAN}

\section{A. Kesimpulan}

1) Terdapat potensi panorama alam yaitu Curug Leles, Tenjo Gunung, Taman Air Terjun, Camping Ground serta terdapat 42 jenis potensi flora dan 22 jenis potensi fauna.

2) Strategi yang dapat diterapkan dalam pengembangan obyek wisata alam Bumi Perkemahan Leles TNGC adalah strategi SO (Strengths-Opportunities) yaitu mendukung strategi agresif dengan cara Mengembangkan semua potensi-potensi yang dimiliki bekerjasama dengan masyarakat sekitar dengan merancang design penataan yang unik serta menumbuhkan dan meningkatkan sadar konservasi melalui pendidikan dan penyuluhan kepada pengelola, masyarakat dan pengunjung. Kawasan wisata alam Bumi Perkemahan Leles TNGC bisa dijadikan sebagai wisata pendidikan untuk pelajar yang berkunjung dengan menambah pengetahuan pelajar mengenai jenis satwa dan tumbuhan. Memelihara fasilitas yang ada agar bisa digunakan untuk jangka panjang serta untuk kenyamanan pengunjung serta menambah fasilitas yang kurang memadai.

\section{B. Saran}

1) Perlu adanya peningkatan promosi melalui media elektronik dan media masa tentang potensi Obyek Wisata Bumi Perkemahan Leles TNGC.

2) Perlu adanya peningkatan kuantitas dan kualitas Sumber Daya Manusia (Karyawan) dengan cara melaksanakan kegiatan pendidikan dan pelatihan agar terciptanya pengelolaan dan penataan yang baik terhadap Kawasan Bumi Perkemahan Leles TNGC.

3) Menambah fasilitas yang kurang memadai agar menciptakan rasa nyaman bagi pengunjung.

4) Meningkatkan kerjasama antara pihak MPGC dan BTNGC serta menjalin kerjasama dengan instansi - instansi lainnya seperti pemerintah daerah, dinas pariwisata, dan masyarakat sangat diperlukan.

5) Perlu adanya penelitian lanjutan mengenai analisis vegetasi dan inventarisasi satwa. 


\section{DAFTAR PUSTAKA}

Ading. 2010. Studi Pengembangan Faktor Internal dan Eksternal Kawasan Wisata Alam Lembah Cilengkrang Kabupaten Kuningan (skripsi). Kuningan: Program Sarjana, Universitas Kuningan.

Aryanti, Nita Septi. 2013. Analisis Pengaruh Kualitas Sumber Daya Manusia terhadap Strategi Pemasaran dan Pelayanan di Desa Wisata Kebonagung Imogiri Bantul (tugas akhir). Yogyakarta: Program Diploma III, Universitas Gadjah Mada.

Darmawan, D. dan Fadjarajani, S. 2016. Hubungan antara pengetahuan dan sikap pelestarian lingkungan dengan perilaku wisatawan dalam menjaga kebersihan lingkungan (studi di kawasan objek wisata alam gunung galunggung desa linggajati kecamatan sukaratu kabupaten tasikmalaya). Jurnal Geografi. 4 (1): Hal 37-49.

Fathoni, Abdurrahmat. 2011. Metodologi Penelitian \& Teknik Penyusunan Skripsi. Jakarta : PT Rineka Cipta.

Flamin, A. dan Asnaryati. 2013. Potensi ekowisata dan strategi pengembangan Tahura Nipa-Nipa, Kota Kendari, Sulawesi Tenggara. Jurnal Penelitian Kehutanan Wallacea. 2 (2): Hal $154-156$.

Hakim, A. 2012. Ekowisata. Jurnal Ekowisata. Purwokerto: Jurusan Biologi UNSOED.

Latupapua, Y. 2007. Studi potensi kawasan dan pengembangan ekowisata di Tual Kabupaten Maluku Tenggara. Jurnal Agroforestri. 2 (1): Hal 65-71.
Lucyanti, R. Hendrarto, B dan Izzati, M. 2014. Strategi pengembangan obyek wisata bumi perkemahan palutungan berdasarkan analisis daya dukung lingkungan wisata di Taman Nasional Gunung Ciremai Kabupaten Kuningan Propinsi Jawa Barat. Jurnal ekosains. 6 (1): Hal $34-36$.

Meyers, Koen. 2009. Panduan Dasar Pelaksanaan Ekowisata. Jakarta: Technical Adviser for Environmental Sciences UNESCO.

National Park Board. 2013. Flora and Fauna. Singapore: National Parks.

Priyanto, R. Syarifuddin, D. Martina, S. 2018. Perancangan model wisata edukasi di objek wisata kampung tulip. Jurnal Pengabdian Kepada Masyarakat. Hal 32-38.

Sofia Nuraeni, B. 2014. Analisis faktor-faktor yang mempengaruhi minat kunjung ulang wisatawan museum ranggawarsita Semarang. Jurnal Bisnis Strategi. 23 (1): Hal 1-20.

Yanto, I. 2010. Analisis Strategi Pengelolaan dan Pengembangan Obyek Wisata Bumi Perkemahan Palutungan Gunung Ciremai Kabupaten Kuningan (skripsi). Fakultas Kehutanan, Universitas Kuningan. Kuningan

Zulhijja, L. dan Azzuhri, M.

Pengaruh Pelatihan dan Pengembangan Sumber Daya Manusia terhadap Organizational Citizenship Behavior dan Kinerja Pegawai pada Dinas Kebudayaan dan Pariwisata Kabupaten Kediri”. Hal 1-14 